This item was submitted to Loughborough's Research Repository by the author.

Items in Figshare are protected by copyright, with all rights reserved, unless otherwise indicated.

\title{
Sponsees matter! How collective responsibility judgments of sport sponsors affect sponsee equity
}

\section{PLEASE CITE THE PUBLISHED VERSION}

https://doi.org/10.1080/16184742.2019.1631365

\section{PUBLISHER}

Routledge (Taylor \& Francis Group) / @ European Association for Sport Management

\section{VERSION}

AM (Accepted Manuscript)

\section{PUBLISHER STATEMENT}

This is an Accepted Manuscript of an article published by Taylor \& Francis in European Sport Management Quarterly on 25 Jun 2019, available online: https://doi.org/10.1080/16184742.2019.1631365

\section{LICENCE}

CC BY-NC-ND 4.0

\section{REPOSITORY RECORD}

Dickenson, Peter, and Anne Souchon. 2019. "Sponsees Matter! How Collective Responsibility Judgments of Sport Sponsors Affect Sponsee Equity”. Loughborough University. https://hdl.handle.net/2134/37953. 
Sponsees matter!

How collective responsibility judgments of sport sponsors affect sponsee equity

\begin{abstract}
Research question: Previous research has focused on sport sponsors, with little known on how sponsorship affects sponsee equity (e.g. audiences' behaviors towards sponsees). Further, sponsorship research typically ignores concurrent sponsors, which are naturally perceived in terms of perceived 'groupness' (entitativity). In turn, entitativity will affect people's judgments of the collective responsibility (CR) sponsors have towards the properties they are associated with. To compound the issue, sponsees' dependence on sponsors typically affords the latter authority that can also affect the CR people perceive sponsors have. We therefore examine how people's concurrent sponsors' entitativity and perceived authority influence sponsee equity through CR.
\end{abstract}

Research methods: Data were collected from 255 (Study one) and 233 (Study two) consumers in a European country. Data collection consisted of scenario-based surveys. Responses were analyzed via structural equation modeling using Lisrel.

Results and Findings: We find that entitativity and perceived authority are related to people's inferences of omission, which consistently drives collective responsibility. However, the effect of inferences of commission on collective responsibility may be affected by the (non)official status of the sponsors. Meanwhile, entitativity and authority are also found to be linked to collective responsibility, which is itself related to sponsee equity. 
Implications: Theoretically, we advance knowledge of sponsee equity drivers by applying knowledge/theories from social psychology. Managerially, the findings suggest opportunities should be created for sponsors to be entitative and as having an authority over the sponsee.

Keywords: concurrent sponsorship, entitativity, perceived authority, collective responsibility, sponsee equity 


\section{Introduction}

Sport sponsorship is both a rapidly growing communication platform (Kim, Lee, Magnusen, \& Kim, 2015; Zarantonello \& Schmitt, 2013), and an increasingly rich field of academic study (Bouchet, Doellman, Troilo, \& Walkup, 2017; Yang \& Goldfarb, 2015). In this context, research tends to focus on how sponsorship influences attitudes and behaviors towards a sponsor (Biscaia, Correia, Rosado, Ross, \& Maroco, 2013). Insufficient studies have so far examined how sponsee equity is affected by sponsorship (Chavanat, Martinent, \& Ferrand, 2009). Sponsee equity is defined as a behavioral construct of audience's propensity to watch a sponsored event (Ruth \& Simonin, 2006; Olson, 2010). In the words of Olson (2010, p. 187), 'with only a few exceptions...sponsorship theory and research has almost entirely focused on the effects that the sponsorship has on the sponsor, while ignoring the potential effects on the object'. Yet, sponsorship effectiveness can (and should) be examined from sponsee rights-holders' (e.g. an event-governing body (see Kulczycki \& Koenigstorfer, 2016)) perspectives too (Groza, Cobbs, \& Schaefers, 2012). Notably, sponsorship allows sponsees to be financially viable (Mazodier, Quester, \& Chandon, 2012; Witcher, Craigen, Culligan, \& Harvey, 1991). It may also create image spillovers that affect how audiences perceive (Henseler, Wilson, \& de Vreede, 2009), and behave towards, sponsees (Olson, 2010), and/or can be harnessed to create a better service experience for audiences (cf. Jae Ko, Zhang, Cattani, \& Pastore, 2011; Rundh \& Gottfridsson, 2015; Tax, McCutcheon, \& Wilkinson, 2013). Ultimately, sponsee rights-holders have sponsorship agendas beyond funding of events, the objectives of which might be strategic (Wolfe, Meenaghan, \& O'Sullivan, 1997) and/or marketing-related (O'Reilly \& Huybers, 2015) 
in a bid to increase sponsee viewership. Hence, the impact of sponsorship on sponsees is both relatively under-studied and yet of practical relevance.

Further, much sport sponsorship research examines individual sponsors in isolation from the other sponsors of the same property (Chavanat et al., 2009). This ignores the fact that most sponsees tend to have multiple, concurrent sponsors (Boronczyk, Rumpf, \& Breuer, 2018; Carrillat, Harris, \& Lafferty, 2010; Carrillat, Solomon, \& d'Astous, 2015; Ruth \& Simonin, 2006). Concurrent sponsors are an aggregate of social entities. Social psychology research shows that individuals naturally perceive aggregates of social entities along a continuum of perceived 'groupness' (Hamilton, Sherman, \& Lickel, 1998), called entitativity (Dasgupta, Banaji, \& Abelson, 1999; Hamilton, 2007), and that groupness perceptions (i.e. entitativity) result in altered social attitudes and behaviors towards the group (Cavazza, Pagliaro, \& Guidetti, 2014). By extension, an audience's 'groupness' perceptions (i.e. entitativity) of concurrent sponsors should affect responses towards the sponsee (cf. Authors, 2018; Groza et al., 2012; Henseler et al., 2009; Ruth \& Simonin, 2006). Indeed, we observe increased instances in sponsees turning away from title-sponsorship, and towards multiple-sponsor models (e.g. English football Premier League; UEFA Champions' League), which they promote as a group (e.g. London 2012 Olympic Games), in a bid to raise the global reach of their competitions (e.g. Spanish La Liga and La Liga 2).

Higher entitativity of aggregates has been found to result in higher collective responsibility (CR) judgments of the group (Denson, Lickel, Curtis, Stenstrom, \& Ames, 2006), whereby responsibility is attributed to 'others' beyond those directly responsible for an event (Lickel, Schmader, \& Hamilton, 2003). Collective responsibility has also been found to be contingent on the authority the group is perceived to have over the event (cf. Lickel, Hamilton, \& 
Sherman, 2001). Authority is concerned with the (perceived) influence sponsors have over the sponsored property (cf. Kahn \& Kram, 1994). In sporting contexts, while rights-holders are directly responsible for the running of an event, sponsors are also often perceived to be at least partly responsible. In turn, and given the established link between entitativity and authority, and collective responsibility, concurrent sponsors who are perceived as more 'group-like' (i.e. entitative) and/or having a greater authority over events should be attributed greater collective responsibility than they otherwise would be. While social psychology studies mainly focus on the negative consequences of $\mathrm{CR}$ judgments (where, for example, blame is assigned for criminal acts), collective responsibility is also linked with positive responses (see Adelman, Yogeeswaran, \& Lickel, 2019; Kou \& Stewart, 2018). With respect to sport sponsorship, perceptions of concurrent sponsors' collective responsibility may in fact benefit sponsees; sponsorship is a function of an event audience's appeal (Kim \& Chalip, 2004), and enhanced sponsors' responsibility perceptions generated from concurrent sponsorship contexts signal a more professionally-run and prominent event (see Authors, 2018). Thus, a virtuous circle may exist whereby concurrent sponsorships signal to audiences that properties are increasingly worth following.

Yet, despite the ubiquity of concurrent sponsors, the fact that they will be perceived on an entitativity continuum (i.e. ranging from low to high) (Hamilton et al., 1998) by nature of being social aggregates (MacInnis \& Folkes, 2017), and that both entitativity and authority are related to collective responsibility judgments, little is known about how sponsee equity can be enhanced via (perceived) collective responsibility of concurrent sponsors.

Finally, as sponsorship is 'an investment, in cash or in kind, in an activity [owned by a third party] in return for access to the exploitable commercial potential associated with that 
activity' (Meenaghan, 1991, p. 36), it is clear that there are two distinct types of sponsors: those that invest financial resources, and those that invest in-kind resources (such as the use of branded products), to sponsees. Yet, existing sports sponsorship research tends not to differentiate between the two different categories of sponsors. This is potentially problematic insofar as different types of sponsors will have different sponsorship objectives (Carrillat \& d'Astous, 2012), and may consequently be perceived differently by audiences. In turn, different perceptions of sponsors may lead to the sponsee being perceived differently (Henseler et al., 2009). Hence, studies that differentiate between the two types of sponsors can help unmask potentially different effects of variations in perceptions that studies which amalgamate the two hide.

The paper's objectives are to address these gaps. More specifically, we examine how entitativity and perceived authority towards sponsors impact upon sponsee equity through collective responsibility, separating financial and in-kind sponsorships. We make three key contributions to the sports sponsorship domain. First, we address calls in the literature for further understanding into how sponsorship affects sponsee equity (Olson, 2010). With much of the literature focusing on sponsoring brands' equity outcomes of sponsorship (Chavanat et al., 2009), drivers of sponsee equity are often overlooked. Second, we examine concurrent sponsorship contexts (Carrillat et al., 2010), and by natural association, draw on entitativity ('groupness' perceptions) and perceived authority found in social aggregate contexts (e.g. Lickel, Hamilton, Wieczorkowska, Lewis, Sherman, \& Uhles, 2000; Lickel et al., 2001). In so doing, we build on and extend Authors' (2018, Study 2) work by empirically assessing the mechanisms by which entitativity of concurrent sponsors affect sponsee equity through the mediating role of collective responsibility. Further, we advance Authors (2018) by investigating the impact 
perceived sponsors' authority has on collective responsibility judgments and ultimately sponsee equity. In turn, a more fine-grained understanding of the mechanisms linking people's perceptions of concurrent sponsors and sponsee equity materializes. Finally, in distinguishing between financing and in-kind sponsors, we begin to disentangle how audiences' perceptions of different types of sponsors can affect sponsees.

The rest of our paper is set out as follows: we first present the limited sponsee-related literature before offering our conceptual model and corresponding hypotheses. We then describe the methodology employed to test these hypotheses, and outline our findings. These are discussed before implications are drawn in our conclusions. We also suggest a number of avenues for further research.

\section{Background}

Sponsee-related work is under-researched and disjointed (cf. Dietl \& Schweizer, 2014). A review of the literature, however, shows that image transfer (Henseler et al., 2009) and consumer evaluations of events (Ruth \& Simonin, 2006) are perceived as precursors to audience generation (Wolfe et al., 1997). While all three are key sponsorship motivations of sponsees it is the latter, reflected in behavioral intentions towards the sponsee (i.e. watching/following a sponsee), that enables sponsee rights-holders to secure sponsorship agreements (cf. Kim \& Chalip, 2004). In this context, we identify sponsee equity as a key performance metric for sponsee rights' holders, and define it as people's behavioral (viewing) intentions towards a sponsee (e.g. Yang \& Smith, 2009).

Notwithstanding sponsee equity's importance, the scarce sponsorship-related literature suggests, firstly, people are more likely to attend a sponsee in the presence of concurrent sales- 
oriented sponsors than a single sales-oriented sponsor (Ruth \& Simonin, 2006). This is

particularly noteworthy for sporting contexts because (i) concurrent sponsors are the norm, and (ii) people are more likely to perceive sports sponsors as commercially-driven rather than altruistically-driven (e.g. Carrillat \& d'Astous, 2012). Secondly, the presence of a controversial co-sponsor (compared to an uncontroversial co-sponsor) reduces people's attitudes towards the sponsee (Ruth \& Simonin, 2003). This finding can be attributed in part to people's 'fit' perceptions. Indeed, a low-fitting co-sponsor (relative to a high-fitting co-sponsor) reduces people's sponsee quality perceptions (Groza et al., 2012). Consequently, fit is an important driver of sponsorship responses in consumer-based research (e.g. Cornwell, Weeks, \& Roy, 2005), including for consumer responses towards sponsees (Olson, 2010).

\section{Conceptual Model}

People respond to brands in much the same way as they respond to people (Puzakova, Kwak, \& Taylor, 2013) and other social aggregates (MacInnis \& Folkes, 2017), and this is also true in the sports sector (Greenhalgh, Dwyer, \& LeCrom, 2017). Consequently, our conceptual model closely follows Lickel et al.'s (2003) framework on collective responsibility judgments towards people. Specifically, entitativity and authority are expected to influence concurrent sponsors' collective responsibility through two situational construals: inferences of responsibility by commission and inferences of responsibility by omission. Responsibility through an inference of commission is concerned with 'others' being held responsible for an event they are perceived to have facilitated or encouraged. This is due to the 'others' being perceived as having the same attitude as the perpetrator or being glad the perpetrator carried out the act. In a sponsorship context, the same logic could apply, for example, when sponsors are held responsible for the 
competition-level or for creating a festive atmosphere despite the fact it is actually the event owner who is directly responsible (e.g. O'Neill, Getz, \& Carlsen, 1999). By contrast, responsibility through an inference of omission is concerned with 'others' being held responsible for an event they are perceived as able to prevent (May, 1987). For example, people may perceive the 'others' should have known about the perpetrator's intentions and actions. Relating this to sponsorship, Lance Armstrong has argued his sponsors 'should have known that he was doping... [but they] "did nothing”" (Albergotti \& O'Connell, 2013). Lickel et al. (2003) examined collective responsibility within the context of a negative event (namely blaming others for the Columbine high school massacre). Conversely, all else equal, we consider sponsors' collective responsibility to have positive consequences (e.g. Adelman et al., 2019; Kou \& Stewart, 2018). Indeed, sponsorship can generally be considered 'positively valenced' (Pope, Brown, \& Voges, 2009, p. 7). In particular, sponsors' collective responsibility is conceptualized as positively affecting sponsee equity (Authors, 2018). Our conceptual model is outlined in Figure I.

\section{[INSERT FIGURE I ABOUT HERE]}

\section{Hypotheses Development}

The majority of sports events are sponsored by multiple organizations (Ruth \& Simonin, 2006; Chavanat et al., 2009). Thus, audiences are exposed to a variety of different sponsors at once (Boronczyk et al., 2018). In this context, the way people perceive multiple entities affects behaviors (Yzerbyt, Corneille, \& Estrada, 2001), and so the way in which concurrent sponsors are perceived as a group (entitativity) likely affects audiences' behaviors too (Authors, 2018). That said, the mechanisms by which concurrent sponsors' entitativity can affect an audience's 
behavior may be convoluted. Specifically, social psychology research shows that entitativity is tightly connected to perceptions of social influence, and has been shown to predict collective responsibility judgments (Denson et al., 2006). Such judgments occur when responsibility is attributed to 'others' beyond those directly responsible for the event (Feinberg, 1970; Lickel et al., 2003). According to Lickel et al. (2001), people use their knowledge about groups to make inferences about events related to groups, including making judgments of collective responsibility. It has been found that when aggregates are perceived as more 'group-like' (i.e. entitative), they are perceived as being more collectively responsible (Denson et al., 2006). The relationship between entitativity and collective responsibility can be explained through two inferences: omission (failing to act) and commission (facilitating or encouraging the act) (Lickel et al., 2003). In other words, inferences of commission and by omission about the event help form judgments about the collective responsibility 'others' have for a perpetrator's actions. In the context of sponsorship, 'others' refer to sponsors, while the term perpetrator should be replaced with the sponsee rights-holder. In other words, audiences make inferences of commission and omission about the sponsors' involvement in the property they are sponsoring, to inform the perception they form of the sponsors' collective responsibility towards that property.

Sponsee rights-holders have direct responsibility for a sponsee yet sponsors are also attributed some responsibility to sponsees' successes (Messner \& Reinhard, 2012), both in terms of performance (e.g. Formula 1 team performance is partially predicated on the sponsors' car components and engineering, see Cobbs, Tyler, Jensen, \& Chan (2017)), and in terms of financing viability and professional running of the event (e.g. Mazodier et al., 2012). Hence, as entitativity increases, perceived sponsors' collective responsibility towards the sponsee also increases. Subsequently, and following social psychology findings, we first propose that 
entitativity of concurrent sponsors affects the two collective responsibility construals. That is, and applying Lickel et al.'s (2003) and Denson et al.'s (2006) findings to sports contexts, the audience would hold an entitative group of sponsors responsible for (a) stepping in to help run a sponsee if it is being mis-managed (i.e. inference of omission), and (b) facilitating or encouraging the sponsee's rights-holder to run the property in a particular way (i.e. inference of commission). Thus, we expect the following:

H1: Perceptions of concurrent sponsors' groupness (i.e. entitativity) are positively related to inferences of omission.

H2: Perceptions of concurrent sponsors' groupness (i.e. entitativity) are positively related to inferences of commission.

Construals of collective responsibility judgments are not only informed by entitativity (i.e. 'groupness' perceptions) but also by the perceived authority that the group has over the act or event (Lickel et al., 2003). Figures in authority are often held responsible for the actions of their subordinates, even if they had no direct bearing on those actions. In legal settings, for example, 'a state in which it is an accepted doctrine that the sins of the servant may, even when unauthorized, be visited upon the master, has won a tolerable respect for its law' (Laski, 1916, p. 105). Vicarious responsibility therefore exists when liability for an act is shouldered by someone other than the direct perpetrator (Brank, Green, \& Hochevar, 2011). According to Shultz \& Schleifer (1987), vicarious responsibility can be assigned to people who are in a superior relation to the perpetrator, in other words, by people who have authority over the perpetrator. In a sports 
context, perceived authority refers to people's perceptions of sponsors' influence over the sponsee (cf. Kahn \& Kram, 1994). Sponsor influence arises because sport sponsees are increasingly dependent on sponsorship for survival (Mazodier et al., 2012; Witcher et al., 1991). Consequently, sponsors are becoming increasingly powerful in sponsor-sponsee relationships (e.g. Hobbs, 2016), including how sponsees operate (Crompton, 2014). Hence, and as mentioned previously, sponsors can be held accountable for sponsees (Messner \& Reinhard, 2012), and this accountability can take the form of responsibility by omission and commission (Lickel et al., 2003). Thus, as concurrent sponsors are increasingly perceived to have authority over the sponsee, they will be held increasingly responsible for (a) stepping in to support the event if things go awry, and (b) ensuring the event runs as it should. We therefore expect the following:

H3: Perceptions of concurrent sponsors' authority are positively related to inferences of omission.

H4: Perceptions of concurrent sponsors' authority are positively related to inferences of commission.

In turn, responsibility construals (inferences of omission and commission) are purported to affect people's judgments of collective responsibility. According to Lickel et al. (2003), the construals serve to justify self-held beliefs that others are responsible for an act, irrespective of any evidence suggesting others' direct involvement in that act. In a sports context, when concurrent sponsors are held accountable for not stepping in when needed, or for the actual good running of the event, the audience will hold sponsors collectively responsible: 
H5: Inference of commission is positively related to collective responsibility judgments.

H6: Inference of omission is positively related to collective responsibility judgments.

Finally, social psychologists have long been interested in the effects of social influence on behavior (Denson et al., 2006). Visentin, Scarpi, \& Pizzi (2016) signal the importance of studying behaviors in sponsorship research, and this study seeks to uncover sponsorship effects on audiences' behavior towards sponsees. Attributing collective responsibility judgments for the running of sponsees to sponsors emanates from perceptions that these sponsors can positively change the course of the event, insofar as they (i) act as a group, and (ii) have the authority to make the necessary adjustments to a sponsee. The assumption underlying this is that the existence of sponsorship arrangements increases sponsors' say in how a sponsee runs, and this leads to increased professionalism and sponsee quality perceptions (e.g. Delpy, Grabijas, \& Stefanovich, 1998; Roy \& Cornwell, 2003). Subsequently, audiences benefit from perceptions of higher quality sponsees compared to lower quality sponsees, increasing people's propensity to watch the sponsee (Authors, 2018). Hence, we expect that:

H7: Collective responsibility judgments are positively related to sponsee equity.

\section{Methodology}


We conducted two studies, each using a sample of respondents from the population of a single European country drawn from a consumer panel (supplied by the online survey software company, Qualtrics). In the first study, we employed a mixed-design experimental vignette (scenario) methodology (i.e. one where different sets of respondents receive a specific vignettepair incorporating a particular named concurrent sponsor and event in each vignette), also known as a factorial survey experiment (see Atzmüller \& Steiner, 2010), to dissociate in-kind sponsorship contexts from financing sponsorship contexts. Here, we presented the sponsors as having 'official' status (i.e. 'official providers' or 'official financers') to infer a substantial level of sponsorship investment. The two sponsees chosen were the European Games and the National Provincial Championship events. At the time of data collection, the sponsees had been discussed in the media but limited information about the specific events was provided. As such, this study offers a good blend of internal and ecological validity.

In Study two, we matched one prototypical concurrent in-kind sponsor with one event and another prototypical concurrent financing sponsor with another event (see e.g. Carrillat \& d'Astous, 2012). Respondents were also informed that the two 'real' events' names had been deliberately changed so that responses were not biased. Hence, this study also balances internal and ecological validity considerations. Finally, the two sponsorship types were presented simply as either an 'in-kind' concurrent sponsorship or a 'financing' concurrent sponsorship (i.e. no 'official' status was declared), and some measures were adapted or changed (see Study 2 for more details). Hence, Study two represents a constructive replication of Study one.

Following best practice recommendations (Aguinis \& Bradley, 2014), respondents were presented with both the 'in-kind' scenario and the 'financing' scenario. This served to focus respondents' minds on "typical” yet contrasting sponsorship arrangements (see Crawford, 
Sherman, \& Hamilton, 2002; Pappu \& Cornwell, 2014). Nike and Adidas represented the two named prototypical sponsors (Authors, 2018) in both studies.

\section{Study One}

\section{Overview}

A total of eight scenario-pairs were devised, representing a combination of two different sponsees (i.e. European Games/National Provincial Championship), two different named focal concurrent sponsors (i.e. Nike/Adidas), and a counter-balancing of the sponsorship arrangement type (financing/in-kind concurrent sponsorships displayed first) (See Appendix One). For example, in one scenario-pair, the sponsee may be the European Games paired with Nike as the focal concurrent sponsor providing in-kind support. In turn, the second scenario would be the National Provincial Championship paired with Adidas as the focal concurrent sponsor offering financing. Subsequently, each respondent was randomly assigned to one of eight scenario-pairs. Methodologically, randomizing scenario exposure attenuates the risk of method bias (e.g. due to a particular named sponsee or focal concurrent sponsor or the presentation order of scenarios). Nevertheless, we also incorporated a number of conceptual controls at the analysis stage to further mitigate against potential method bias (see below).

Finally, to ensure concurrent sponsorship contexts (and ultimately the bases for a group impression), respondents were told that there were three concurrent sponsors. Consequently, as well as the named prototypical concurrent sponsor provided to respondents, people also named two other concurrent sponsors they believed sponsored the respective event. It was important the sample of the general population chose their own 'other' concurrent sponsors to ensure each 
sponsorship context was relevant to them. Indeed, this is a common methodological approach for scenario-based research involving the general population (e.g. Yi, Kim, \& Hwang, 2017), and is particularly appropriate for sponsorship research, given people's identification of sponsors is 'driven more by a heuristic of mere plausibility [that a brand is a sponsor] than by a direct recollection of the actual sponsors' (Johar, Pham, \& Wakefield, 2006, p. 196). People's responses to the 'other' concurrent sponsors were then 'piped' into the survey-based questions using Qualtrics' functionality so that all three concurrent sponsors' 'fits' with the sponsee could be controlled for. 'Fit' is known to be one of, if not the most important drivers of people's sponsor-property evaluations (e.g. Olson, 2010). Hence, controlling for people's 'fit' also mitigates against potential biases that may arise from people's idiosyncrasies, including from a specific named 'other' sponsor.

The research design followed a preliminary qualitative study designed to complement the literature in identifying the constructs of interest. Where possible, established measures were used, which have proven over the years to be psychometrically sound (e.g., attitude towards sponsorship), and therefore reasonably accessible to respondents. In addition, given some item adaptations necessary to allow for context, the questionnaire was pre-tested by four academic experts in the field and survey research methodology. For example, entitativity items were adapted from Sani (2005) and Sani, Bowe, \& Herrera (2008), authority from Child (1973) and Vroom (1959), inferences of commission and omission from Lickel et al. (2003), collective responsibility from Denson et al. (2006) and Lickel et al. (2003), and sponsee equity from Kim, Trail, \& Ko (2011), Olson (2010), and Speed and Thompson (2000). We also included the conceptual control variables, familiarity with (Machleit, Allen, \& Madden, 1993) and attitude towards (Gwinner \& Bennett, 2008) both the sponsee and focal prototypical concurrent sponsor, 
attitude towards the sponsorship (Simonin \& Ruth, 1998), fit between the three concurrent sponsors and the sponsee (Speed \& Thompson, 2000), and event membership (i.e. the extent to which the sponsee is part of the sponsorship group) (Graf, Schuh, Van Quaquebeke, \& van Dick, $2012)^{1}$. The sponsorship-related controls are known to influence sponsee equity (e.g. Olson, 2010), while the event membership control was intended to subtly capture the perceived social influence sponsors have over rights-holders (and/or their events) due to the latter potentially being seen as part of the sponsorship collective.

Analysis was undertaken on 255 completed surveys, which is above the suggested minimum threshold of 200 responses needed for structural equation modeling (SEM) analysis. First, differences between people's responses exposed to a specific (i) financing (i.e. 'Official Financers') and (ii) in-kind (i.e. ('Official Providers') scenario were tested for. As expected, Kruskal-Wallis tests indicated no significant differences in responses (all $p \mathrm{~s}>.05$ ) across the financing, nor the in-kind sponsorships, enabling all randomized financing/in-kind scenarios to be collapsed into one overall 'financing' and one overall 'in-kind' sponsorship context. In other words, only the distinctive contexts of in-kind and financing concurrent sponsorships were retained, which is the main difference of interest for this study's purpose (see e.g. Mutz, 2011)). Next, our model was tested using SEM via Lisrel 8.71. The use of SEM analysis across respondents in factorial survey experiments is appropriate, given the focus on relationships between independent and dependent variables (see Cohen, 1968), and that each respondent was essentially exposed to the same financing/in-kind scenario for the purposes of this study (Aguinis $\&$ Bradley, 2014). The sample composed of $49.4 \%$ female and a mean age $=40.5$ years Meanwhile, the average time respondents had lived in the country as a percentage of age $=91.5 \%$.

\footnotetext{
${ }^{1}$ We note responses to entitativity and sponsee equity (and some conceptual controls) were also utilized in Authors (2018, Study 2). Responses to all other substantive constructs, as well as the testing of the hypothesized relationships, are new contributions to literature.
} 
This high percentage is important because it minimizes the possibility of bias due to extraneous factors resulting from culture (e.g. Kashima et al., 2005; Spencer-Rodgers, Williams, \& Peng, 2012; Spencer-Rodgers, Williams, Hamilton, Peng, \& Wang, 2007), sport (e.g. Lüschen, 1967), and/or sponsorship inferences (e.g. Marshall \& Cook, 1992; Mazodier \& Rezaee, 2013).

We tested for common method bias using Podsakoff, MacKenzie, Lee, \& Podsakoff (2003). Specifically, we informed respondents that there were no right or wrong answers and that their responses were anonymous. In terms of analytical procedures, we first undertook a Harman single factor test. As expected, poor fit indices and significant $\Delta \chi^{2}$ were found in both sponsorship contexts (financing sponsors: $\Delta \chi^{2}(105)=6871$; in-kind sponsors: $\Delta \chi^{2}(105)=6702$ ). Second, we utilized social desirability as a common method factor. For both the financing $\left(\Delta \chi^{2}(41)=21.451\right)$ and the in-kind $\left(\Delta \chi^{2}(41)=31.818\right)$ sponsors, nonsignificant $\Delta \chi^{2}$ were found, indicating CMV is of little-to-no concern.

\section{Results}

The measurement model was tested for both forms of sponsorship separately. In both cases, confirmatory factor analysis (CFA) showed acceptable fit indices. More specifically, the CFA for in-kind sponsors returns $\chi^{2}(825)=1428 ; \mathrm{RMSEA}=.0512 ; \mathrm{SRMR}=.0332 ; \mathrm{NNFI}=.984 ; \mathrm{CFI}=.987$.

CFA results for financing sponsors are as follows: $\chi^{2}(825)=1441$; RMSEA=.0511;

$\mathrm{SRMR}=.0348 ; \mathrm{NNFI}=.983 ; \mathrm{CFI}=.986$.

The lowest factor loading across both sponsorship types is .794, and the highest error variance .369 , demonstrating psychometrically sound measures. Meanwhile, construct reliability (CR), the square root of the average variance extracted $(\sqrt{A V E})$, and discriminant validity are also all within acceptable boundaries for both sponsor types. Notably, all AVEs are above the 0.5 threshold and the $\sqrt{A V E}$ are higher than the highest correlation they share with another variable. 
Hence, discriminant validity can be deemed to have been upheld in both in-kind and financing sponsors (Fornell \& Larcker, 1981). The supplementary file outlines the correlation matrices, $\sqrt{A V E} \mathrm{~s}$, and CRs for both sponsor types, as well as details of measurement items, factor loadings, and error variances.

The conceptual model was tested on both the in-kind and financing sponsorship contexts. SEM analysis demonstrates overall fit indices were within acceptable thresholds for both sponsorship types. However, an examination of the modification indices suggested people's attitude towards the sponsorship (a conceptual control) should also be linked to collective responsibility judgments and the two associated construals in both sponsorship contexts, whilst direct paths from entitativity and authority to collective responsibility were also suggested. Finally, the modification indices also suggested the fit of the prototypical concurrent sponsor should be directly linked to inferences of commission in the in-kind sponsorship context. Based on post-hoc logical reasoning, we created these links and also included direct paths from the 'fits' of the other two (respondent identified) sponsors to inferences of commission in the in-kind sponsorship context. This is justified given the prototypical sponsor's link. Subsequently, the SEM for in-kind sponsors returns $\chi^{2}(854)=1509$; RMSEA=.0527; SRMR=.0385; NNFI=.984; CFI=.986. The parallel SEM results for financing sponsors are as follows: $\chi^{2}(857)=1526$; $\mathrm{RMSEA}=.0528 ; \mathrm{SRMR}=.0422 ; \mathrm{NNFI}=.982 ; \mathrm{CFI}=.985$.

Path results obtained indicate six of the seven hypotheses are supported (5\% directional significance level) in both sponsorship contexts. Specifically, both entitativity $\left(\gamma_{\text {in-kind }}=.242\right.$ / $\left.p<.001 ; \gamma_{\text {financing }}=.238 / p<.001\right)$ and authority $\left(\gamma_{\text {in-kind }}=.176 / p=.003 ; \gamma_{\text {financing }}=.234 / p<.001\right)$ are positively related to commission, supporting hypotheses 1 and 2 in both sponsorship contexts. Percentage of variance explained $\left(\mathrm{R}^{2}\right)$ for inference of commission is $58.2 \%$ for in-kind sponsors 
and 54.0\% for financing sponsors. Likewise, entitativity $\left(\gamma_{\text {in-kind }}=.178 / p=.005 ; \gamma_{\text {financing }}=.126 /\right.$ $p=.035)$ and authority $\left(\gamma_{\text {in-kind }}=.481 / p<.001 ; \gamma_{\text {financing }}=.399 / p<.001\right)$ are positively related to omission, supporting hypotheses 3 and 4 for both sponsorship types, respectively. For inference of omission, $\mathrm{R}^{2}$ is $57.2 \%$ for in-kind sponsors and $52.3 \%$ for financing sponsors. Meanwhile, we find no evidence of inference of commission being positively related to sponsors' collective responsibility. Instead, we find significant and negative relationships between inferences of commission and collective responsibility in the in-kind concurrent sponsorship context $\left(\beta_{\text {in-kind }}=\right.$ $.122 / p=.025)$ and a marginally significant and negative relationship in the financing concurrent sponsorship context $\left(\beta_{\text {financing }}=-.104 / p=.053\right)$. Therefore, hypothesis 5 is not supported in either sponsorship arrangement. Conversely, omission is positively related to collective responsibility, supporting Hypothesis 6 ( $\left.\beta_{\text {in-kind }}=.378 / p<.001 ; \beta_{\text {financing }}=.384 / p<.001\right)$. Further, and as expected, entitativity $\left(\gamma_{\text {in-kind }}=.203 / p<.001 ; \gamma_{\text {financing }}=.215 / p<.001\right)$ and authority $\left(\gamma_{\text {in-kind }}=.284 /\right.$ $\left.p<.001 ; \gamma_{\text {financing }}=.318 / p<.001\right)$ are also positively related to collective responsibility. The percentage of variance explained for collective responsibility is $66.2 \%$ for in-kind sponsors and $60.9 \%$ for financing sponsors. Collective responsibility is positively related to sponsee equity for both sponsorship contexts, supporting Hypothesis 7 ( $\beta_{\text {in-kind }}=.351 / p<.001 ; \beta_{\text {financing }}=.241 /$ $p<.001) .70 .8 \%$ of sponsee equity's variance is explained for in-kind sponsors while $70.7 \%$ is explained for financing sponsors. Finally, a number of controls are found to have significant relationships (all results are summarized in Table I).

[INSERT TABLE I ABOUT HERE]

\section{Study Two}




\section{Overview}

Study two was a constructive replication of Study one. Epistemologically-speaking, constructive replications 'seek not "only" to provide additional evidence for or against an existing finding but also to refine or extend findings' (Hüffmeier, Mazei, \& Schultze, 2016, p. 86). As such, they underpin external validity and the accumulation of scientific knowledge (Colquitt, \& ZapataPhelan, 2007). Specifically, two new sponsorship scenarios were created (see Appendix Two) and counterbalanced among respondents. We captured respondents' media consumption habits for two sports, namely, rugby and football (Brown, Billings, Schallhorn, Schramm, \& Devlin, 2016), as part of a wider set of randomized sport media consumption questions to reduce bias. This allowed us to control for people's sport-specific consumption habits when testing the model in each sponsorship context. Similarly, we replaced the 'event membership' question with a perceived 'co-creation' question. This question implicitly captures social influence through items pertaining to interacting with one another, working together, and co-creating (O'Cass \& Ngo, 2011). Finally, we captured people's perceptions of each event's size to mitigate against potential prominence-based heuristics (e.g. Johar \& Pham, 1999; Johar, Pham, \& Wakefield, 2006; Pham \& Johar, 2001).

The 233 completed surveys comprised of $53.2 \%$ female respondents, a mean age $=47.2$ years, with the average time respondents had lived in the country as a percentage of age $=94.1 \%$.

\section{Results}

The CFAs of both the in-kind $\left(\chi^{2}(661)=1180 ;\right.$ RMSEA=.0547; SRMR=.0344; NNFI=.978; $\mathrm{CFI}=.982)$ and financing $\left(\chi^{2}(661)=1122 ; \mathrm{RMSEA}=.0509 ; \mathrm{SRMR}=.0339 ; \mathrm{NNFI}=.983 ; \mathrm{CFI}=.986\right)$ 
sponsorship contexts returned acceptable fit indices. All factor loadings and construct reliabilities (CRs) are also above the accepted thresholds in both contexts. Likewise, the lowest square root of the average variance extracted $(\sqrt{A V E} s)$ is higher than the highest correlation between this variable and others, suggesting discriminant validity is upheld (please see the supplemental file).

Post-hoc analysis of the SEMs intimated a number of direct paths should exist. For example, the modification indices suggested the three sponsors' fits should be directly linked to inferences of commission in the in-kind sponsorship context (in line with Study one). Similarly, a direct path from entitativity to collective responsibility in the financing sponsorship context was also suggested (again, following Study one). In turn, the in-kind sponsorship SEM returns $\chi^{2}(694)=1271 ;$ RMSEA=.0564; SRMR=.0473; NNFI=.977; CFI=.980. The parallel SEM results for financing sponsors are $\chi^{2}(699)=1231 ; \mathrm{RMSEA}=.0540 ; \mathrm{SRMR}=.0468 ; \mathrm{NNFI}=.982 ; \mathrm{CFI}=.984$.

Path results obtained indicate a number of significant and marginally significant relationships, as well as nonsignificant findings. Specifically, while entitativity is nonsignificantly related to commission in the in-kind sponsorship context $\left(\gamma_{\text {in-kind }}=-.031 / p>.10\right)$, it is significantly related in the financing context $\left(\gamma_{\text {financing }}=.398 / p<.001\right)$, thereby providing support for $\mathrm{H} 1$ for the latter sponsorship type. Meanwhile, $\mathrm{H} 2$ is supported in both contexts, with authority being significantly related to commission $\left(\gamma_{\text {in-kind }}=.297 / p<.001 ; \gamma_{\text {financing }}=.401 /\right.$ $p<.001) .57 .4 \%$ of commission's variance is explained in the in-kind sponsorship context, whilst $48.1 \%$ is explained in the financing context. Entitativity $\left(\gamma_{\text {in-kind }}=.182 / p<.001 ; \gamma_{\text {financing }}=.234\right.$ / $p<.001)$ and authority $\left(\gamma_{\text {in-kind }}=.718 / p<.001 ; \gamma_{\text {financing }}=.653 / p<.001\right)$ are both positively related to omission, providing support for hypotheses 3 and 4 in both sponsorship contexts. $69.7 \%$ of omission is explained in the in-kind sponsorship context, whilst $63.7 \%$ is explained in the financing context. 
Commission is marginally significantly related to collective responsibility in the in-kind sponsorship context ( $\left.\beta_{\text {in-kind }}=.078 / p=.089\right)$ and nonsignificantly related in the financing context ( $\left.\beta_{\text {financing }}=-.055 / p>.10\right)$. Therefore, partial support for H5 is found for the in-kind sponsorships but no support is found for the financing sponsors. Conversely, omission ( $\beta_{\text {in-kind }}=.740 / p<.001$; $\left.\beta_{\text {financing }}=.556 / p<.001\right)$ is positively related to collective responsibility for both sponsorship types, supporting hypothesis 6 . As expected, the direct path from entitativity to collective responsibility (from inspection of modification indices) is also significantly related in the financing context $\left(\gamma_{\text {financing }}=.165 / p=.043\right) .43 .9 \%$ of collective responsibility is explained in the in-kind sponsorship context, whilst 53.9\% is explained in the financing context. Finally, collective responsibility is significantly related to sponsee equity in the in-kind $\left(\beta_{\text {in-kind }}=.296\right.$ / $p<.001)$ sponsorship context and marginally significantly related ( $\left.\beta_{\text {financing }}=.085 / p=.08\right)$ in the financing context. $58.3 \%$ of sponsee equity is explained when the sponsors are in-kind sponsors, whilst $63.2 \%$ is explained when the sponsors are financing sponsors.

\section{General Discussion}

Overall, the results of both studies suggest our conceptual model generally holds for both sponsorship types and, importantly, collective responsibility is consistently positively related to sponsee equity. However, notable similarities and differences exist between our findings and that of Lickel et al. (2003), on which our model is primarily based. Specifically, our results follow Lickel et al.'s (2003) results with respect to entitativity and authority being significant drivers of inferences of omission and generally support the view (in three of four cases) that entitativity and authority drive inferences of commission too. In turn, inferences of omission consistently drive 
collective responsibility judgments in both in-kind and financing sponsorship contexts. However, there is mixed support for inferences of commission driving collective responsibility in both concurrent sponsorship contexts. Instead, commission appears to be (marginally) significantly and negatively related to collective responsibility when sponsors are known to have 'official' status, and only marginally significantly and positively related for in-kind sponsors when there is no 'official' status presented. Meanwhile, there is no significant relationship when respondents are not informed of financing sponsors' 'official' status. One possible reason for these contrasting findings may be due to the 'official' status itself. For example, in-kind sponsors are a form of ingredient branding, which 'incorporates functional attributes of the secondary brand[s] into the primary one' (Mazodier \& Merunka, 2014, p. 1553). Here, the in-kind sponsors are the functional-based, secondary brands while the sponsee is the primary brand. In turn, the 'official' status of the in-kind sponsors in Study one may have led people to infer the sponsee is a prominent (large and professionally-run) event. Subsequently, people may see the sponsee rights-holder as increasingly "pulling the strings", resulting in sponsors' respective involvements restricted to the specific functional attribute(s) they provide the sponsee to run. Conversely, and somewhat ironically, when in-kind sponsors are not presented as 'official' they may be seen as investing functional-based resources at a more holistic level. Consequently, the more these sponsors are 'on the same page' as the sponsee rights-holder (i.e. commission), the more likely they are to be held collectively responsible for the event. Finally, both perceived authority and entitativity were found to have direct and positive relationships with collective responsibility, suggesting additional construals link entitativity/authority and collective responsibility.

\section{Theoretical and Managerial Contributions}


Few studies in sponsorship apply knowledge/theories from social psychology to underpin models. Yet, sponsorship is a social phenomenon (Daellenbach, Davies, \& Ashill, 2006; Olkkonen, Tikkanen, \& Alajoutsijarvi, 2000), and the intricacies of, and mechanisms by which, sponsorship outcomes are derived (e.g. purchase intentions towards sponsors, or intentions to watch an event) are largely predicated on consumer behavior principles founded on psychology (see e.g. Cornwell et al., 2005). In this study, we advance our knowledge of people's sponsorship-related responses towards sponsees by anchoring our conceptual development in social psychology, which examines the theory of aggregates (collectives), how they are perceived and how perceptions of them shape behavior. Given the ubiquity of multiple concurrent sponsors to a given sponsee, audiences' impressions of sponsors will be shaped by their perceptions of them as a group, and by the degree to which they are seen to have greater or lesser authority over the sponsee. This organically leads to perceiving sponsors as increasingly responsible for the performance of the sponsee, which in turn, makes the sponsee more attractive to potential audiences (i.e. it's a higher quality product). In this context, we also therefore address a gap in the sport sponsorship literature, which has typically focused on the sponsorrelated benefits of sponsorship, largely overlooking benefits to the sponsee. In particular, and contrary to the vast amount of literature linking collective responsibility to negative consequences (e.g. perceptions of infrahumanization (Castano \& Giner-Sorolla, 2006) or punishment (Pereira, Berent, Falomir-Pichastor, Staerklé, \& Butera, 2015)), we demonstrate collective responsibility can have positive connotations (see e.g. Adelman, Yogeeswaran, \& Lickel, 2019; Kou \& Stewart, 2018). Specifically, we find empirical evidence for a consistent positive link between concurrent sponsors' collective responsibility and sponsee equity. Moreover, in anchoring our work in social psychology, we also advance Lickel et al.'s (2003) 
conceptual framework by providing contextual boundaries pertaining to inferences of commission of concurrent sponsor aggregates. While most of our hypotheses between entitativity and perceived authority, and collective responsibility, follow Lickel et al.'s (2003) findings, we find mixed support for the relationship between people's concurrent sponsors' inferences of commission and collective responsibility, particularly for in-kind sponsors, which suggest both positive and negative relationships. In turn, we begin to unravel potentially important differences between people's perceptions of the two sponsorship types as well as open up further investigative avenues. In particular, our results suggest an interplay exists between the 'official' status of in-kind concurrent sponsors and the link between inferences of commission and collective responsibility. More broadly, it is important researchers place more emphasis on the type of sponsorship involved, particularly if they are interested in examining potential differences between the two concurrent sponsorship contexts on sponsees.

Managerially, the study suggests that, in a sporting event context, sponsee rights-holders and sponsors should create opportunities for the latter to be perceived as more 'group like' (i.e. entitative) and as having an authority over the sponsee. For example, rights-holders should look to copy events such as London 2012 where sponsors were displayed together as a group on billboards. In turn, sponsors' collective responsibility judgments should increase, and enhanced perceptions about the sponsee should follow. People's enhanced sponsee perceptions will not only benefit the sponsee but also the concurrent sponsors indirectly. For example, if more people are interested in watching the sponsored event, a larger audience exists for sponsors' sponsorship-linked communications. That said, it may be difficult for sponsees' rights-holders to create such opportunities, given their cultures are 'built on securing rather than managing 
sponsorships' (Farrelly, 2010, p. 329). Hence, it may fall on the concurrent sponsors themselves to create perceptions of 'groupness' and authority.

The positive relationship between inferences of omission and collective responsibility also suggest concurrent sponsors should direct their communication strategies towards being seen as the "guardians" of a sponsee i.e. the stakeholders that hold sponsee rights-holders to account. In some ways, this is a natural shift from sponsors' historical position. Previously, sponsors were only welcomed by consumers if they maintained the integrity and sanctity of a sponsee (Meenaghan, 2001). Hence, sponsors would tip-toe around a sponsee, ensuring they carefully balanced their own commercial objectives with fans' conditional acceptance of them. Since then, fans have become more accepting of sponsees as brands in their own rights (e.g. Abosag, Roper, \& Hinds, 2012), allowing sponsors more prominence during sponsees’ runnings. In turn, our results suggest concurrent sponsors can seize the opportunity to position themselves as custodians of a sponsee's integrity and sanctity, particularly at a time when rights-holders' practices are being questioned. Indeed, recent high-profile corruption scandals demonstrate sponsors maneuvering themselves into such positions. For example, recent corruption in the IAAF led to its president, Lord Sebastian Coe, stating, 'We have sponsors... watching very carefully how we address the issues facing our sport and facing all sport, as we strive for greater transparency and accountability' (Coe, 2016, p. 5). This approach would also fit with sponsors' recent moves to appear more philanthropic in their respective sponsorships (e.g. Ryan \& Fahy, 2012).

\section{Limitations and Future Research}


As with all research, this study has limitations. Addressing these issues in future research can help further our knowledge of concurrent sponsors' effects on sponsees. For example, we focused on events as sponsees. Events differ from sports teams or athletes, not least because they occur 'rarely' or 'intermittently' to 'draw sizable audiences' (Erickson \& Kushner, 1999, p. 350). Event rights-holders are also often reliant on sponsors for their events to run in the first place (Mazodier et al., 2012; Witcher et al., 1991). As such, the extent to which our model holds for athlete or team contexts needs further consideration. For instance, rivalry is known to be particularly important for these contexts (e.g. Tyler \& Cobbs, 2015), and may therefore be an important moderator between sponsors' entitativity and authority, and sponsee equity. Indeed, fans may be accepting of sponsors' collective responsibility (and the commercialization that comes with this), if it helps them win (cf. Abosag et al., 2012). Conversely, our model may only be relevant to event-based contexts.

In line with our sponsorship definition, we focused on consumers' responses within financial and nonfinancial sponsorship contexts. These two scenarios also enabled us to balance the need for distinct sponsorship contexts (Crawford et al., 2002) against the need to minimize potential respondent fatigue. However, a multitude of sponsorship characteristics are likely to affect sponsee equity. For example, Woisetschläger, Backhaus, \& Cornwell (2017) examined how contract length, sponsor proximity, sponsorship fee, and the type of sponsorship (e.g. shirt sponsorship, stadium naming rights) affected consumers' affective, normative, and calculative sponsorship attributions. In turn, their results suggest affective motives positively influence sponsee equity while calculative motives negatively affect sponsee equity. Future research should therefore consider how (non)financial sponsorship contexts and other sponsorship characteristics interact to affect sponsee equity as well as subsequent sponsor-related outcomes. 
We allowed respondents to choose two 'other' concurrent sponsors alongside the prototypical focal concurrent sponsors (i.e. Nike/Adidas). While this is a legitimate methodological approach (e.g. Yi et al., 2017), and respondents' three sponsor-event fit perceptions were controlled for, future research may consider using existing concurrent sponsorship set-ups. Although this brings its own challenges (e.g. balancing the number of actually sponsors associated with a sponsee against respondent fatigue resulting from asking multiple sponsor-related questions), ecological validity will be further enhanced.

This research was also undertaken in a single country. However, previous research has suggested responses to both sponsorship (e.g. Marshall \& Cook, 1992; Mazodier \& Rezaee, 2013) and social aggregate contexts (Spencer-Rodgers et al., 2012; Spencer-Rodgers et al., 2007) are country-/culture- dependent. Consequently, the extent to which our findings hold across different countries/cultures is an important contribution to the literature.

Outside of the study's limitations a number of possible research directions arise. From a consumer's perspective, understanding the interaction between 'official' status and outcomes of entitativity in both sponsorship contexts is worthy of further investigation. Indeed, there is some, albeit limited evidence to suggest an interaction between title sponsorships and entitativity may affect consumers' sponsee evaluations (cf. Groza et al., 2012). Another research direction pertains to concurrent sponsors' (perceived) increasing responsibility in a sponsee as a result of entitativity and perceived authority. This is likely to become progressively linked to the satisfaction people expect from consuming that sponsee. In turn, sponsors will be perceived as being increasingly fundamental to a sponsee's overall service offering (cf. Rundh \& Gottfridsson, 2015; Tax et al., 2013). At least two potential research questions follow: First, if people's expected satisfaction levels are not met, will perceptions of increased sponsor collective 
responsibility lead to exacerbated negative responses towards sponsors? Conversely, will negative responses towards sponsee rights-holders be attenuated? Understanding people's responses to potential service-failure situations has important implications for service-recovery strategies for both sponsors and sponsee rights-holders. Second, previous research has suggested people are 'indifferent' to ambush marketing (Shani \& Sandler, 1998, p. 378). Yet ambush marketing activities 'represent one of the biggest threats to the future of major sport events because they strike at the heart of the deals that finance them' (Mazodier et al., 2012, p. 193). Subsequently, and as a result of entitativity and authority perceptions, will people's attitude towards ambush marketing activities shift to a more extreme (and likely negative) position if they perceive concurrent sponsors are increasingly responsible for a sponsee's happening? Answering this question may create further safeguarding opportunities for sponsors' investments.

Ambush marketing-related questions also arise from an organizational perspective. For example, would entitative concurrent sponsors reduce the likelihood that a sponsee is targeted by ambush marketers? Social psychology literature informs us that entitative groups are perceived to have the potency to act, "where potency implies the capacity to do either good or bad things... [which] enables a group to be ready and able to act collectively and thus to be impactful' (Sherman, Hamilton, \& Lewis, 1999, p. 100). Meanwhile, entitative groups that are capable of acting (i.e. retaliating) inhibit hostility from out-group members (Newheiser \& Dovidio, 2015). Relating this to concurrent sponsorship contexts, potential ambush marketers - in this case, the out-group member - may be deterred from targeting a sponsee if it thinks entitative concurrent sponsors are able to retaliate. Given sport sponsees' reliance on sponsorship for their existence, 
the extent to which (potential) ambush marketers' activities are affected by (in)entitative concurrent sponsors, is worthy of investigation. 


\section{References}

Abosag, I., Roper, S., \& Hind, D. (2012). Examining the relationship between brand emotion and brand extension among supporters of professional football clubs. European Journal of Marketing, 46, 1233-1251.

Adelman, L., Yogeeswaran, K., \& Lickel, B. (2019). They're all the same, sometimes: Prejudicial attitudes toward Muslims influence motivated judgments of entitativity and collective responsibility for an individual's actions. Journal of Experimental Social Psychology, 80, 31-38.

Aguinis, H., \& Bradley, K. J. (2014). Best practice recommendations for designing and implementing experimental vignette methodology studies. Organizational Research Methods, 17, 351-371.

Albergotti, R. \& O'Connell, V. (2013, July 23). Armstrong Seeks Dismissal of Federal Whistleblower Suit. Wall Street Journal. Retrieved April 12, 2018 from https://www.wsj.com/articles/SB10001424127887324328904578624563537684642

Atzmüller, C., \& Steiner, P. M. (2010). Experimental vignette studies in survey research. Methodology, 6, 128-138.

Authors. (2018). Entitativity of concurrent sponsors: Implications for properties and sponsors. Journal of Advertising, forthcoming. DOI: 10.1080/00913367.2018.1466219.

Biscaia, R., Correia, A., Rosado, A. F., Ross, S. D., \& Maroco, J. (2013). Sport sponsorship: The relationship between team loyalty, sponsorship awareness, attitude toward the sponsor, and purchase intentions. Journal of Sport Management, 27, 288-302.

Boronczyk, F., Rumpf, C., \& Breuer, C. (2018). Determinants of viewer attention in concurrent event sponsorship. International Journal of Sports Marketing and Sponsorship, 19(1), 11- 
24.

Bouchet, A., Doellman, T. W., Troilo, M., \& Walkup, B. R. (2017). Preempting the competition: How do shareholders view sponsorships in the sport apparel industry?. Journal of Sport Management, 31, 1-38.

Brank, E. M., Greene, E., \& Hochevar, K. (2011). Holding parents responsible: Is vicarious responsibility the public's answer to juvenile crime? Psychology, Public Policy, and Law, $17,507-529$.

Brown, K. A., Billings, A. C., Schallhorn, C., Schramm, H., \& Devlin, N. A. (2016). Power within the Olympic rings? Nationalism, Olympic media consumption, and comparative cases in Germany and the USA. The Journal of International Communication, 22, 143169.

Carrillat, F. A., \& d'Astous, A. (2012). The sponsorship-advertising interface: is less better for sponsors?. European Journal of Marketing, 46, 562-574.

Carrillat, F. A., Harris, E. G., \& Lafferty, B. A. (2010). Fortuitous brand image transfer. Journal of Advertising, 39, 109-124.

Carrillat, F. A., Solomon, P. J., \& d'Astous, A. (2015). Brand Stereotyping and Image Transfer in Concurrent Sponsorships. Journal of Advertising, 44, 300-314.

Castano, E., \& Giner-Sorolla, R. (2006). Not quite human: Infrahumanization in response to collective responsibility for intergroup killing. Journal of Personality and Social Psychology, 90, 804-818.

Cavazza, N., Pagliaro, S., \& Guidetti, M. (2014). Antecedents of concern for personal reputation: The role of group entitativity and fear of social exclusion. Basic and Applied Social Psychology, 36, 365-376. 
Chavanat, N., Martinent, G., \& Ferrand, A. (2009). Sponsor and sponsees interactions: Effects on consumers' perceptions of brand image, brand attachment, and purchasing intention. Journal of Sport Management, 23, 644-670.

Child, J. (1973). Strategies of control and organizational behavior. Administrative Science Quarterly, 18, 1-17.

Cobbs, J., Tyler, D., Jensen, J.A., \& Chan, K. (2017). Prioritizing sponsorship resources in formula one racing: A longitudinal analysis. Journal of Sport Management, 31, 96-110.

Coe, S. (2016). Time for Change. Retrieved May 3, 2018 from https://www.iaaf.org/aboutiaaf/documents/iaaf-reform.

Cohen, J. (1968). Multiple regression as a general data-analytic system. Psychological Bulletin, $70,426-443$.

Colquitt, J. A., \& Zapata-Phelan, C. P. (2007). Trends in theory building and theory testing: A five-decade study of the Academy of Management Journal. Academy of Management Journal, 50, 1281-1303.

Cornwell, T. B., Weeks, C. S., \& Roy, D. P. (2005). Sponsorship-linked marketing: Opening the black box. Journal of Advertising, 34, 21-42.

Crawford, M. T., Sherman, S. J., \& Hamilton, D. L. (2002). Perceived entitativity, stereotype formation, and the interchangeability of group members. Journal of Personality and Social Psychology, 83, 1076-1094.

Crompton, J. L. (2014). Potential negative outcomes from sponsorship for a sport property. Managing Leisure, 19, 420-441.

Daellenbach, K., Davies, J. \& Ashill, N.J. (2006). Understanding sponsorship and sponsorship relationships - multiple frames and multiple perspectives. International Journal of 
Nonprofit and Voluntary Sector Marketing, 11(1), 73-87.

Dasgupta, N., Banaji, M. R., \& Abelson, R. P. (1999). Group entitativity and group perception: Associations between physical features and psychological judgment. Journal of Personality and Social Psychology, 77, 991-1003.

Delpy, L., Grabijas, M., \& Stefanovich, A. (1998). Sport tourism and corporate sponsorship: A winning combination. Journal of Vacation Marketing, 4, 91-102.

Denson, T. F., Lickel, B., Curtis, M., Stenstrom, D. M., \& Ames, D. R. (2006). The roles of entitativity and essentiality in judgments of collective responsibility. Group Processes \& Intergroup Relations, 9, 43-61.

Dietl, H. M., \& Schweizer, N. (2014). Developing a framework to identify and systematise sources of inefficiencies in sports sponsorship from a sponsee perspective. International Journal of Sport Management and Marketing, 15, 36-56.

Erickson, S.G., \& Kushner, J.R. (1999). Public event networks: an application of marketing theory to sporting events. European Journal of Marketing, 33, 348-365.

Farrelly, F. (2010). Not playing the game: Why sport sponsorship relationships break down. Journal of Sport Management, 24, 319-337.

Farrelly, F., Quester, P., \& Greyser, S. A. (2005). Defending the co-branding benefits of sponsorship B2B partnerships: The case of ambush marketing. Journal of Advertising Research, 45, 339-348.

Feinberg, J. (1970). Doing and Deserving; Essays in the Theory of Responsibility. Princeton, NJ: Princeton University Press.

Fornell, C., \& Larcker, D. F. (1981). Evaluating structural equation models with unobservable variables and measurement error. Journal of Marketing Research, 18, 39-50. 
Graf, M. M., Schuh, S. C., Van Quaquebeke, N., \& van Dick, R. (2012). The relationship between leaders' group-oriented values and follower identification with and endorsement of leaders: The moderating role of leaders' group membership. Journal of Business Ethics, $106,301-311$.

Greenhalgh, G., Dwyer, B., \& LeCrom, C. (2017). A Case of Multiple (Brand) Personalities: Expanding the Methods of Brand Personality Measurement in Sport Team Contexts. Sport Marketing Quarterly, 26, 20-30.

Groza, M. D., Cobbs, J., \& Schaefers, T. (2012). Managing a sponsored brand: The importance of sponsorship portfolio congruence. International Journal of Advertising, 31, 63-84.

Gwinner, K., \& Bennett, G. (2008). The impact of brand cohesiveness and sport identification on brand fit in a sponsorship context. Journal of Sport Management, 22, 410-426.

Hamilton, D. L. (2007). Understanding the complexities of group perception: Broadening the domain. European Journal of Social Psychology, 37, 1077-1101.

Hamilton, D. L., Sherman, S. J., \& Lickel, B. (1998). Perceiving Social Groups: The Importance of the Entitativity Continuum. In C. Sedikide, J. Schopler, \& C.A. Insko (Eds.), Intergroup Cognition and Intergroup Behavior (pp. 47-74). Mahwah, NJ: Lawrence Erlbaum.

Henseler, J., Wilson, B. \& De Vreede, D. (2009). Can sponsorships be harmful for events? Investigating the transfer of associations from sponsors to events. International Journal of Sports Marketing and Sponsorship, 10(3), 47-54.

Hobbs, T. (2016). Why Adidas is re-evaluating its Relationship with Athletics. Retrieved April 16, 2018 from https://www.marketingweek.com/2016/01/25/why-adidas-is-re-evaluatingits-relationship-with-athletics/.

Hüffmeier, J., Mazei, J., \& Schultze, T. (2016). Reconceptualizing replication as a sequence of 
different studies: A replication typology. Journal of Experimental Social Psychology, 66, 81-92.

Jae Ko, Y., Zhang, J., Cattani, K., \& Pastore, D. (2011). Assessment of event quality in major spectator sports. Managing Service Quality: An International Journal, 21, 304-322.

Jensen, J. A., \& Cornwell, T. B. (2017). Why do marketing relationships end? Findings from an integrated model of sport sponsorship decision-making. Journal of Sport Management, 31, 401-418.

Johar, G. V., \& Pham, M. T. (1999). Relatedness, prominence, and constructive sponsor identification. Journal of Marketing Research, 299-312.

Johar, G. V., Pham, M. T., \& Wakefield, K. L. (2006). How event sponsors are really identified: A (baseball) field analysis. Journal of Advertising Research, 46, 183-198.

Kahn, W. A., \& Kram, K. E. (1994). Authority at work: Internal models and their organizational consequences. Academy of Management Review, 19, 17-50.

Kashima, Y., Kashima, E., Chiu, C. Y., Farsides, T., Gelfand, M., Hong, Y. Y., \& Yzerbyt, V. (2005). Culture, essentialism, and agency: Are individuals universally believed to be more real entities than groups?. European Journal of Social Psychology, 35, 147-169.

Kim, N. S., \& Chalip, L. (2004). Why travel to the FIFA World Cup? Effects of motives, background, interest, and constraints. Tourism Management, 25, 695-707.

Kim, Y., Lee, H. W., Magnusen, M. J., \& Kim, M. (2015). Factors influencing sponsorship effectiveness: A meta-analytic review and research synthesis. Journal of Sport Management, 29, 408-425.

Kim, Y. K., Trail, G., \& Ko, Y. J. (2011). The influence of relationship quality on sport consumption behaviors: An empirical examination of the relationship quality framework. 
Journal of Sport Management, 25, 576-592.

Kou, C. Y., \& Stewart, V. (2018). Group Accountability: A Review and Extension of Existing Research. Small Group Research, 49, 34-61.

Laski, H. J. (1916). The basis of vicarious liability. The Yale Law Journal, 26, 105-135.

Lickel, B., Hamilton, D. L., \& Sherman, S. J. (2001). Elements of a lay theory of groups: Types of groups, relational styles, and the perception of group entitativity. Personality and Social Psychology Review, 5, 129-140.

Lickel, B., Hamilton, D. L., Wieczorkowska, G., Lewis, A., Sherman, S. J., \& Uhles, A. N. (2000). Varieties of groups and the perception of group entitativity. Journal of Personality and Social Psychology, 78, 223-246.

Lickel, B., Schmader, T., \& Hamilton, D. L. (2003). A case of collective responsibility: Who else was to blame for the Columbine High School shootings?. Personality and Social Psychology Bulletin, 29, 194-204.

Lüschen, G. (1967). The interdependence of sport and culture. International Review of Sport Sociology, 2, 127-141.

Machleit, K. A., Allen, C. T., \& Madden, T. J. (1993). The mature brand and brand interest: An alternative consequence of ad-evoked affect. Journal of Marketing, 57(4), 72-82.

MacInnis, D. J., \& Folkes, V. S. (2017). Humanizing brands: When brands seem to be like me, part of me, and in a relationship with me. Journal of Consumer Psychology, 27, 355-374.

Marshall, D., \& Cook, G. (1992). Does sponsorship always talk the same language? An overview of how attitudes to sponsorship vary across Europe. In Sponsorship Europe'92 Conference Proceedings (pp. 151-171). Maarssen: ESOMAR.

May, L. (1987). The Morality of Groups. Notre Dame, IN: Notre Dame Press. 
Mazodier, M., \& Merunka, D. (2012). Achieving brand loyalty through sponsorship: the role of fit and self-congruity. Journal of the Academy of Marketing Science, 40, 807-820.

Mazodier, M., \& Merunka, D. (2014). Beyond brand attitude: Individual drivers of purchase for symbolic cobranded products. Journal of Business Research, 67, 1552-1558.

Mazodier, M., Quester, P., \& Chandon, J-L. (2012). Unmasking the ambushers: Conceptual framework and empirical evidence. European Journal of Marketing, 46, 192-214.

Mazodier, M., \& Rezaee, A. (2013). Are sponsorship announcements good news for the shareholders? Evidence from international stock exchanges. Journal of the Academy of Marketing Science, 41, 586-600.

Meenaghan, T. (1991). The role of sponsorship in the marketing communications mix. International Journal of Advertising, 10, 35-47.

Meenaghan, T. (2001). Understanding sponsorship effects. Psychology \& Marketing, 18, 95-122. Messner, M., \& Reinhard, M-A. (2012). Effects of strategic exiting from sponsorship after negative event publicity. Psychology \& Marketing, 29, 240-256.

Mutz, D. C. (2011) Population-Based Survey Experiments. Oxford: Princeton University Press.

Newheiser, A. K., \& Dovidio, J. F. (2015). High outgroup entitativity can inhibit intergroup retribution. British Journal of Social Psychology, 54, 341-358.

O'Cass, A., \& Ngo, L. V. (2011). Examining the firm's value creation process: a managerial perspective of the firm's value offering strategy and performance. British Journal of Management, 22, 646-671.

O’Neill, M., Getz, D., \& Carlsen, J. (1999). Evaluation of service quality at events: The 1998 Coca-Cola masters surfing event at Margaret river, Western Australia. Managing Service Quality: An International Journal, 9, 158-166. 
O’Reilly, N., \& Huybers, T. (2015). Servicing in sponsorship: A best-worst scaling empirical analysis. Journal of Sport Management, 29, 155-169.

Olkkonen, R., Tikkanen, H., \& Alajoutsijarvi, K. (2000). Sponsorship as relationships and networks: Implications for research. Corporate Communications: An International Journal, 5, 1-12.

Olson, E. L. (2010). Does sponsorship work in the same way in different sponsorship contexts?. European Journal of Marketing, 44, 180-199.

Pappu, R., \& Cornwell, T. B. (2014). Corporate sponsorship as an image platform: understanding the roles of relationship fit and sponsor-sponsee similarity. Journal of the Academy of Marketing Science, 42, 490-510.

Pereira, A., Berent, J., Falomir-Pichastor, J. M., Staerklé, C., \& Butera, F. (2015). Collective punishment depends on collective responsibility and political organization of the target group. Journal of Experimental Social Psychology, 56, 4-17.

Pham, M. T., \& Johar, G. V. (2001). Market prominence biases in sponsor identification: Processes and consequentiality. Psychology \& Marketing, 18, 123-143.

Podsakoff, P.M., MacKenzie, S.B., Lee, J.Y., \& Podsakoff, N.P. (2003). Common method biases in behavioral research: A critical review of the literature and recommended remedies. Journal of Applied Psychology, 88, 879-903.

Pope, N., Voges, K. E., \& Brown, M. (2009). Winning ways. Journal of Advertising, 38, 5-20.

Puzakova, M., Kwak, H., \& Taylor, C. R. (2013). The role of geography of self in "filling in" brand personality traits: Consumer inference of unobservable attributes. Journal of Advertising, 42, 16-29.

Rundh, B., \& Gottfridsson, P. (2015). Delivering sports events: the arena concept in sports from 
a network perspective. Journal of Business \& Industrial Marketing, 30, 785-794.

Ruth, J. A., \& Simonin, B. L. (2003). "Brought to you by Brand A and Brand B" Investigating Multiple Sponsors' Influence On Consumers' Attitudes Toward Sponsored Events. Journal of Advertising, 32, 19-30.

Ruth, J. A., \& Simonin, B. L. (2006). The power of numbers: Investigating the impact of event roster size in consumer response to sponsorship. Journal of Advertising, 35, 7-20.

Ryan, A., \& Fahy, J. (2012). Evolving priorities in sponsorship: From media management to network management. Journal of Marketing Management, 28, 1132-1158.

Sani, F. (2005). When subgroups secede: Extending and refining the social psychological model of schism in groups. Personality and Social Psychology Bulletin, 31, 1074-1086.

Sani, F., Bowe, M., \& Herrera, M. (2008). Perceived collective continuity and social well-being: exploring the connections. European Journal of Social Psychology, 38, 365-374.

Shani, D., \& Sandler, D. M. (1998). Ambush marketing: is confusion to blame for the flickering of the flame?. Psychology \& Marketing, 15, 367-383.

Sherman, S. J., Hamilton, D. L., Lewis, A. C. (1999). Perceived entitativity and the social identity value of group memberships. In D. Abrams \& M.A. Hogg (Eds.), Social Identity and Social Cognition (pp. 80-110), Oxford: Blackwell Publishing.

Shultz, T. R., Jaggi, C., \& Schleifer, M. (1987). Assigning vicarious responsibility. European Journal of Social Psychology, 17, 377-380.

Simonin, B. L., \& Ruth, J. A. (1998). Is a company known by the company it keeps? Assessing the spillover effects of brand alliances on consumer brand attitudes. Journal of Marketing Research, 35, 30-42.

Speed, R., \& Thompson, P. (2000). Determinants of sports sponsorship response. Journal of the 
Academy of Marketing Science, 28, 226-238.

Spencer-Rodgers, J., Williams, M. J., \& Peng, K. (2012). Culturally based lay beliefs as a tool for understanding intergroup and intercultural relations. International Journal of Intercultural Relations, 36, 169-178.

Spencer-Rodgers, J., Williams, M. J., Hamilton, D. L., Peng, K., \& Wang, L. (2007). Culture and group perception: Dispositional and stereotypic inferences about novel and national groups. Journal of Personality and Social Psychology, 93, 525-543.

Tax, S. S., McCutcheon, D., \& Wilkinson, I. F. (2013). The service delivery network (SDN) a customer-centric perspective of the customer journey. Journal of Service Research, 16, $454-470$.

Tyler, B. D., \& Cobbs, J. B. (2015). Rival conceptions of rivalry: Why some competitions mean more than others. European Sport Management Quarterly, 15, 227-248.

Visentin, M., Scarpi, D., \& Pizzi, G. (2016). From assessment to purchase: A three-stage model of the marketing funnel in sponsorship activities. Journal of Sport Management, 30, 615628.

Vroom, V. H. (1959). Some personality determinants of the effects of participation. Journal of Abnormal and Social Psychology, 59, 322-327.

Witcher, B., Craigen, J. G., Culligan, D., \& Harvey, A. (1991). The links between objectives and function in organizational sponsorship. International Journal of Advertising, 10, 13-33.

Woisetschläger, D. M., Backhaus, C., \& Cornwell, T. B. (2017). Inferring corporate motives: How deal characteristics shape sponsorship perceptions. Journal of Marketing, 81, 121141.

Wolfe, R., Meenaghan, T., \& O'Sullivan, P. (1997). Sport, media and sponsor--The shifting 
balance of power in the sports network. Irish Marketing Review, 10, 53-66.

Yang, Y., \& Goldfarb, A. (2015). Banning controversial sponsors: understanding equilibrium outcomes when sports sponsorships are viewed as two-sided matches. Journal of Marketing Research, 52, 593-615.

Yang, X., \& Smith, R. E. (2009). Beyond attention effects: Modeling the persuasive and emotional effects of advertising creativity. Marketing Science, 28, 935-949.

Yi, Y., Kim, S. Y., \& Hwang, J. W. (2017). Climbing down the ladder makes you play it safe: The effect of the status of a rejecter on product evaluation. European Journal of Marketing, 51, 946-959.

Yzerbyt, V., Corneille, O., \& Estrada, C. (2001). The interplay of subjective essentialism and entitativity in the formation of stereotypes. Personality and Social Psychology Review, 5, 141-155.

Zarantonello, L., \& Schmitt, B. H. (2013). The impact of event marketing on brand equity: The mediating roles of brand experience and brand attitude. International Journal of Advertising, 32, 255-280. 


\begin{tabular}{|c|c|c|c|}
\hline Pair & Factor Levels & "IN-KIND " SPONSORS & "FINANCING" SPONSORS \\
\hline & & $\begin{array}{l}\text { The National Provincial Championship is the longest } \\
\text { running rugby competition in New Zealand and is } \\
\text { often a launching platform for many of the game's } \\
\text { biggest stars. The event has a group of THREE } \\
\text { sponsors associated with it. They are collectively } \\
\text { known as 'OFFICIAL PROVIDERS' because they } \\
\text { give products, services and/or expertise to the event. } \\
\text { The group of sponsors do not give money though. } \\
\text { Sponsors in this group have their own specific task } \\
\text { or role within the event. Adidas is one of the event's } \\
\text { 'OFFICIAL PROVIDERS' and will supply its new } \\
\text { 'A1' rugby ball as the match ball. Adidas will also } \\
\text { be promoting the release of its 'A1' rugby ball on } \\
\text { television throughout the competition. }\end{array}$ & $\begin{array}{l}\text { The European Games is a new multi-sport } \\
\text { tournament and is designed as the launching } \\
\text { platform for Europe's athletes to compete on the } \\
\text { world stage. The event has a group of THREE } \\
\text { sponsors associated with it. They are collectively } \\
\text { known as 'OFFICIAL FINANCERS' because they } \\
\text { give money to the event. The group of sponsors do } \\
\text { not give their products, services and/or expertise } \\
\text { though. Sponsors in this group have comparable } \\
\text { brand images. Nike is one of the event's } \\
\text { 'OFFICIAL FINANCERS'. Television } \\
\text { advertisements promoting Nike's new 'DM } \\
\text { Questra' cross-training shoe will also be shown } \\
\text { during the event. }\end{array}$ \\
\hline & Event & National Provincial Championship & European Games \\
\hline $1 / 2^{*}$ & $\begin{array}{l}\text { Focal Concurrent Sponsor } \\
\text { Promoted Product }\end{array}$ & $\begin{array}{l}\text { Adidas } \\
\text { Al rugby ball }\end{array}$ & $\begin{array}{l}\text { Nike } \\
\text { DM Ouestracross-training shoe }\end{array}$ \\
\hline $3 / 4^{*}$ & $\begin{array}{l}\text { Event } \\
\text { Focal Concurrent Sponsor } \\
\text { Promoted Product }\end{array}$ & $\begin{array}{l}\text { European Games } \\
\text { Adidas } \\
\text { DM Questra cross-training shoe }\end{array}$ & $\begin{array}{l}\text { National Provincial Championship } \\
\text { Nike } \\
\text { A1 rugby ball }\end{array}$ \\
\hline $5 / 6^{*}$ & $\begin{array}{l}\text { Event } \\
\text { Focal Concurrent Sponsor } \\
\text { Promoted Product }\end{array}$ & $\begin{array}{l}\text { National Provincial Championship } \\
\text { Nike } \\
\text { Al rugby ball }\end{array}$ & $\begin{array}{l}\text { European Games } \\
\text { Adidas } \\
\text { DM Questra cross-training shoe }\end{array}$ \\
\hline $7 / 8^{*}$ & $\begin{array}{l}\text { Event } \\
\text { Focal Concurrent Sponsor } \\
\text { Promoted Product }\end{array}$ & $\begin{array}{l}\text { European Games } \\
\text { Nike } \\
\text { DM Questra cross-training shoe }\end{array}$ & $\begin{array}{l}\text { National Provincial Championship } \\
\text { Adidas } \\
\text { Al rugby ball }\end{array}$ \\
\hline
\end{tabular}

*counter-balanced vignette-pair: 'Official Financers' presented before 'Official Providers' 


\section{Appendix Two: Study Two Vignettes}

\begin{tabular}{|c|c|}
\hline "IN-KIND" SPONSORS & "FINANCING" SPONSORS \\
\hline $\begin{array}{l}\text { The "Champions Crown" is a long-running } \\
\text { football competition. The event is sponsored } \\
\text { by THREE sponsors. They are collectively } \\
\text { known as 'IN-KIND SPONSORS' because } \\
\text { they invest products, services and/or expertise } \\
\text { in the event. The THREE sponsors do not } \\
\text { invest money though. Each sponsor has its } \\
\text { own specific task or role within the event. } \\
\text { Adidas is one of the event's 'IN-KIND } \\
\text { SPONSORS' and its new 'A1' ball is the } \\
\text { event's official 'match ball'. Throughout the } \\
\text { duration of the event, Adidas also promotes } \\
\text { the release of its latest 'A1' ball on television. }\end{array}$ & $\begin{array}{l}\text { The "Star Cup" is one of the longest } \\
\text { running rugby competitions in the world. } \\
\text { The event is sponsored by THREE } \\
\text { sponsors. They are collectively known as } \\
\text { 'FINANCING SPONSORS' because they } \\
\text { invest money in the event. The THREE } \\
\text { sponsors do not invest products, services } \\
\text { and/or expertise though. All three sponsors } \\
\text { have similar brand images. Nike is one of } \\
\text { the event's 'FINANCING SPONSORS'. } \\
\text { Television advertisements promoting } \\
\text { Nike's new 'DM Questra' cross-training } \\
\text { shoe will also be shown during the event. }\end{array}$ \\
\hline
\end{tabular}




\begin{tabular}{|c|c|c|c|c|c|c|c|c|c|}
\hline \multicolumn{2}{|c|}{ Table I: Structural Model Results } & \multicolumn{4}{|c|}{ Study 1} & \multicolumn{4}{|c|}{ Study 2} \\
\hline & & $\beta / \gamma$ & t-value & $\beta / \gamma$ & t-value & $\beta / \gamma$ & t-value & $\beta / \gamma$ & t-value \\
\hline H1 & Entitativity & .242 & 3.280 & .238 & 3.279 & -.031 & $-.371 \mathrm{~ns}$ & .398 & 5.570 \\
\hline $\mathrm{H} 2$ & Authority over event & .176 & 2.730 & .234 & 3.928 & .297 & 4.138 & .401 & 5.611 \\
\hline Control $^{\text {ph }}$ & Attitude towards the sponsee sponsorship & .398 & 4.855 & .395 & 5.661 & $\mathrm{n} / \mathrm{a}$ & $\mathrm{n} / \mathrm{a}$ & $\mathrm{n} / \mathrm{a}$ & $\mathrm{n} / \mathrm{a}$ \\
\hline Control $^{\text {ph }}$ & Co-creation & $\mathrm{n} / \mathrm{a}$ & $\mathrm{n} / \mathrm{a}$ & $\mathrm{n} / \mathrm{a}$ & $\mathrm{n} / \mathrm{a}$ & .366 & 4.267 & $\mathrm{n} / \mathrm{a}$ & $\mathrm{n} / \mathrm{a}$ \\
\hline Control $^{\text {ph }}$ & Fit of third concurrent sponsor & -.118 & $-1.490^{+}$ & $\mathrm{n} / \mathrm{a}$ & $\mathrm{n} / \mathrm{a}$ & -.268 & -1.757 & $\mathrm{n} / \mathrm{a}$ & $\mathrm{n} / \mathrm{a}$ \\
\hline \multicolumn{2}{|c|}{ Dependent var: Inferences of omission } & \multicolumn{2}{|c|}{$57.2 \%$} & \multicolumn{2}{|c|}{$52.3 \%$} & \multicolumn{2}{|c|}{$69.7 \%$} & \multicolumn{2}{|c|}{$63.7 \%$} \\
\hline $\mathrm{H} 3$ & Entitativity & .178 & 2.607 & .126 & 1.816 & .182 & 3.279 & .234 & 4.222 \\
\hline $\mathrm{H} 4$ & Authority over event & .481 & 7.577 & .399 & 6.774 & .718 & 11.809 & .653 & 10.580 \\
\hline Control $^{\text {ph }}$ & Attitude towards the sponsee sponsorship & .213 & 3.479 & .332 & 5.007 & $\mathrm{n} / \mathrm{a}$ & $\mathrm{n} / \mathrm{a}$ & $\mathrm{n} / \mathrm{a}$ & $\mathrm{n} / \mathrm{a}$ \\
\hline Control $^{\text {ph }}$ & Co-create & $\mathrm{n} / \mathrm{a}$ & $\mathrm{n} / \mathrm{a}$ & $\mathrm{n} / \mathrm{a}$ & $\mathrm{n} / \mathrm{a}$ & $\mathrm{n} / \mathrm{a}$ & $\mathrm{n} / \mathrm{a}$ & .238 & 2.645 \\
\hline Control $^{\text {ph }}$ & Attitude towards the sponsee sponsorship & .235 & 3.773 & .155 & 2.335 & $\mathrm{n} / \mathrm{a}$ & $\mathrm{n} / \mathrm{a}$ & $\mathrm{n} / \mathrm{a}$ & $\mathrm{n} / \mathrm{a}$ \\
\hline \multicolumn{2}{|c|}{ Dependent var: Sponsee equity } & \multicolumn{2}{|c|}{$70.8 \%$} & \multicolumn{2}{|c|}{$70.7 \%$} & \multicolumn{2}{|c|}{$58.3 \%$} & \multicolumn{2}{|c|}{$63.2 \%$} \\
\hline $\mathrm{H} 7$ & Collective responsibility & .351 & 6.352 & .241 & 4.331 & .296 & 5.777 & .085 & $1.401^{+}$ \\
\hline Control $^{\mathrm{c}}$ & Event membership of sponsorship group & .041 & $.668 \mathrm{~ns}$ & .080 & $1.355^{+}$ & $\mathrm{n} / \mathrm{a}$ & $\mathrm{n} / \mathrm{a}$ & $\mathrm{n} / \mathrm{a}$ & $\mathrm{n} / \mathrm{a}$ \\
\hline Control $^{\mathrm{c}}$ & Co-creation & $\mathrm{n} / \mathrm{a}$ & $\mathrm{n} / \mathrm{a}$ & $\mathrm{n} / \mathrm{a}$ & $\mathrm{n} / \mathrm{a}$ & -.240 & -3.341 & .033 & $.408 n s$ \\
\hline Control $^{\mathrm{c}}$ & Attitude towards the sponsee sponsorship & .416 & 5.541 & .410 & 5.768 & .639 & 7.865 & .544 & 6.697 \\
\hline Control $^{\mathrm{c}}$ & Fit of focal prototypical concurrent sponsor & -.191 & -3.017 & -.139 & -2.458 & -.020 & $-.169 n s$ & -.153 & $-1.610^{+}$ \\
\hline Control $^{\mathrm{c}}$ & Fit of second concurrent sponsor & .008 & $.123 \mathrm{~ns}$ & .193 & 2.760 & -.212 & -1.766 & -.173 & $-1.249 \mathrm{~ns}$ \\
\hline Control $^{\mathrm{c}}$ & Fit of third concurrent sponsor & .251 & 3.928 & .066 & $1.100 \mathrm{~ns}$ & .207 & 1.653 & .328 & 2.672 \\
\hline Control $^{\mathrm{c}}$ & Familiarity with focal prototypical concurrent sponsor & -.015 & $-.244 n s$ & .029 & $.405 \mathrm{~ns}$ & .021 & $.301 \mathrm{~ns}$ & -.108 & $-1.478^{+}$ \\
\hline Control $^{\mathrm{c}}$ & Attitude towards focal prototypical concurrent sponsor & -.045 & $-.748 \mathrm{~ns}$ & -.071 & $-.949 n s$ & -.026 & $-.367 \mathrm{~ns}$ & .166 & 2.286 \\
\hline
\end{tabular}




\begin{tabular}{|c|c|c|c|c|c|c|c|c|c|}
\hline Control $^{\mathrm{c}}$ & Familiarity with sponsee & .302 & 4.801 & .227 & 3.705 & $\mathrm{n} / \mathrm{a}$ & $\mathrm{n} / \mathrm{a}$ & $\mathrm{n} / \mathrm{a}$ & $\mathrm{n} / \mathrm{a}$ \\
\hline Control $^{\mathrm{c}}$ & Attitude towards sponsee & -.239 & -3.835 & -.075 & $-1.027 \mathrm{~ns}$ & $\mathrm{n} / \mathrm{a}$ & $\mathrm{n} / \mathrm{a}$ & $\mathrm{n} / \mathrm{a}$ & $\mathrm{n} / \mathrm{a}$ \\
\hline Control $^{\mathrm{c}}$ & Involvement with sporting events in general & .119 & 2.667 & .051 & $1.110 \mathrm{~ns}$ & .152 & 2.355 & .118 & 2.109 \\
\hline Control $^{\mathrm{c}}$ & Media Consumption of football / rugby & $\mathrm{n} / \mathrm{a}$ & $\mathrm{n} / \mathrm{a}$ & $\mathrm{n} / \mathrm{a}$ & $\mathrm{n} / \mathrm{a}$ & .212 & 3.283 & .191 & 3.658 \\
\hline Control $^{\mathrm{c}}$ & Event size & $\mathrm{n} / \mathrm{a}$ & $\mathrm{n} / \mathrm{a}$ & $\mathrm{n} / \mathrm{a}$ & $\mathrm{n} / \mathrm{a}$ & -.093 & -2.061 & -.048 & $-1.078 \mathrm{~ns}$ \\
\hline
\end{tabular}

Notes: ${ }^{\mathrm{c}}=$ conceptual ${ }^{\mathrm{ph}}=$ post-hoc $;{ }^{+}=$marginally significant; $\mathrm{ns}=$ not significant $(p>.1)$ 
Figure I: Conceptual Model

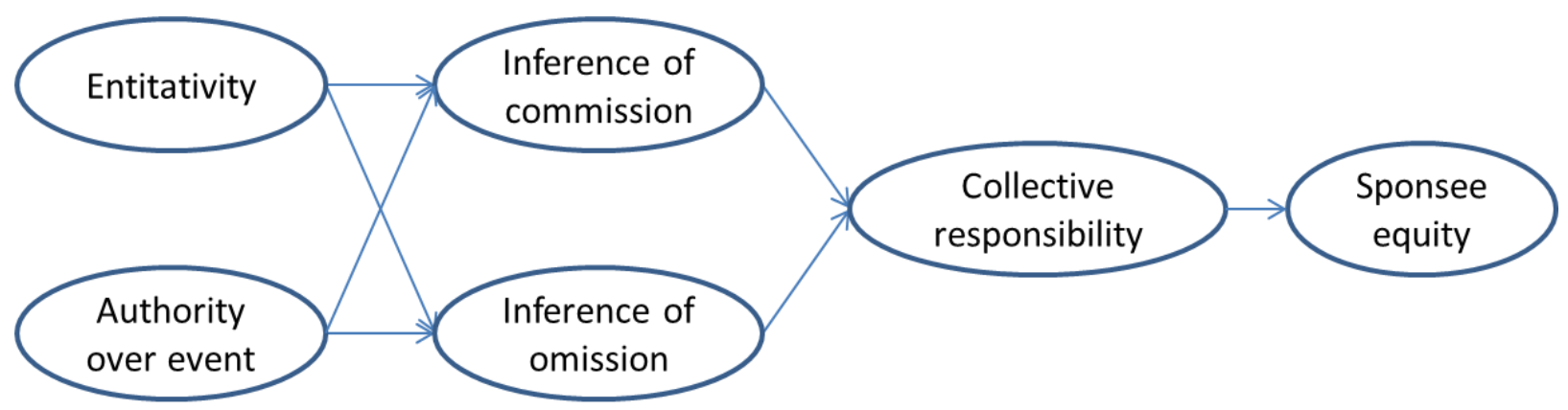

